\title{
FLUIDODINÂMICA COMPUTACIONAL DO ESCOAMENTO DO AR EM MEIO POROSO APLICADO À SECAGEM SOLAR DE FOLHAS DE MORINGA OLEÍFERA EM LEITO FIXO
}

\author{
A.C.R. STOPPE ${ }^{1}$, J.L. VIEIRA NETO ${ }^{1}$, K.G. SANTOS ${ }^{1 *}$ \\ ${ }^{1}$ Universidade Federal Do Triângulo Mineiro, Departamento de Engenharia Química \\ E-mail para contato: kassia.santos@uftm.edu.br
}

\begin{abstract}
RESUMO - Equipamentos que usam energia limpa tem ganhado destaque nos últimos anos. Para aperfeiçoar um secador solar de leito fixo foi estudada a desidratação de folhas de Moringa Oleífera. As simulações CFD mostraram um aumento da velocidade de ar dentro do leito nos dois casos estudados: totalmente aberto e quando cinco entradas de ar superiores eram fechadas. Os testes experimentais de secagem das folhas de Moringa apontaram que o que mais influenciou o aumento de temperatura no leito foi a radiação solar e não o tempo. Também foi eficiente em relação à diminuição do teor de umidade. Quanto ao tipo de configuração, notou-se que o leito parcialmente fechado secou as partículas de forma mais intensa e homogênea. As modificações no secador o tornaram mais eficiente e com secagem mais rápida.
\end{abstract}

\section{INTRODUÇÃO}

A pesquisa e desenvolvimento de equipamentos que operam com fontes de energias limpas estão cada vez mais presente nos meios acadêmicos e industriais. $\mathrm{O}$ aprimoramento desses aparelhos torna-se necessário, aumentando assim sua eficiência e vida útil. Com o intuito de manufaturar produtos que proporcionem uma melhoria social à comunidade, $\mathrm{o}$ aprimoramento de um secador solar de leito fixo já existente na universidade, foi estudado na desidratação de folhas de Moringa Oleífera. Neste trabalho o desenvolvimento de técnicas para aperfeiçoar a eficiência do secador é explanado e através de simulações computacionais e experimentos de secagem comprovaram a eficácia dos métodos empregados.

\section{MÉTODOS}

\subsection{Unidade Experimental e Caracterização do material particulado}

A geometria do equipamento se encontrava como demonstrado na Figura 1. Onde na Fig. 1a do secador completo o número 1 indica o leito vertical, o número 2 o exaustor, 3 a caixa de vidro, 4 a placa metálica posterior, 5 e 6 os refletores e 7 a base do equipamento. Já na Fig. 1b do leito a numeração indica as oito aberturas de entrada de ar. Fig. 1c e Fig. 1d apresentam as modificações quanto a entrada lateral de ar nos dois casos estudados.

Foram pesadas 20 amostras, com 15 folhas cada, e aferida a largura das folhas empregando um micrometro. $\mathrm{O}$ diâmetro médio de área projetada e a esfericidade foram obtidos por análise de imagem empregando o software ImageJ ${ }^{\circledR}$. A massa média total de folhas inseridas no leito fixo foi de $1,4 \mathrm{Kg}$, obtendo-se densidade aparente de $0,546 \mathrm{~g} / \mathrm{cm}^{3}$; esfericidade de 0,435 , diâmetro médio de $0,015 \mathrm{~m}$ e porosidade do leito de 0,679 . 


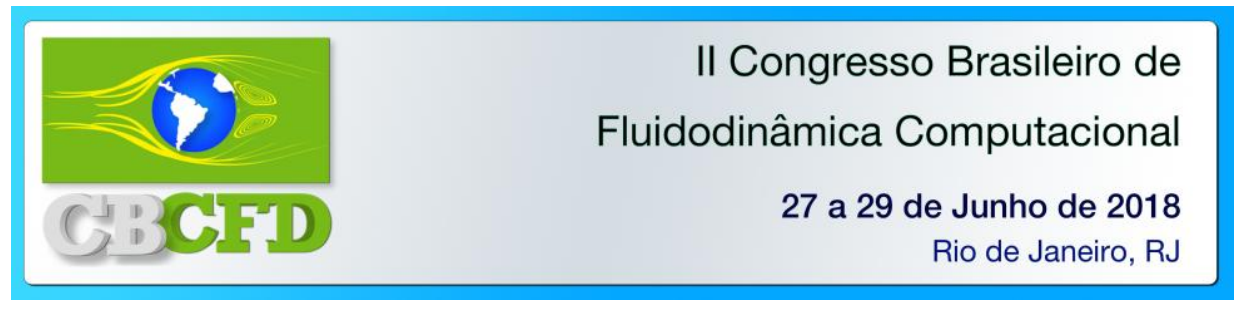

(a)

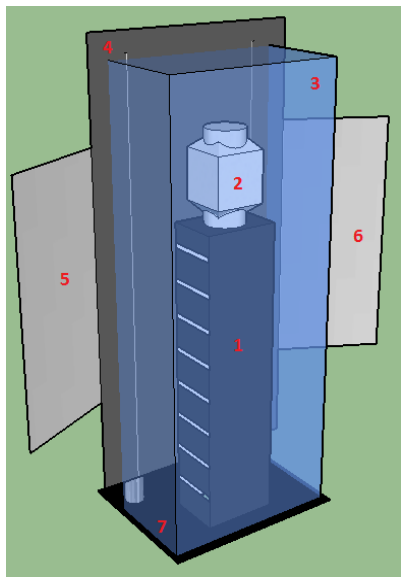

(b)

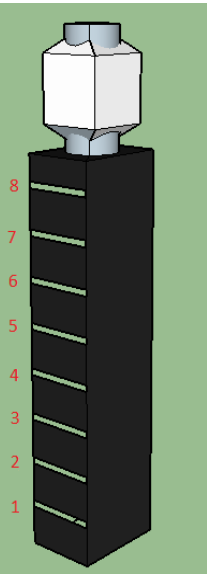

(c)

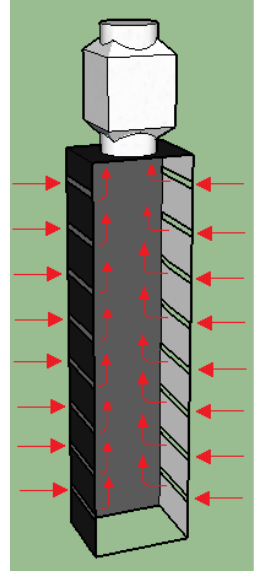

(d)

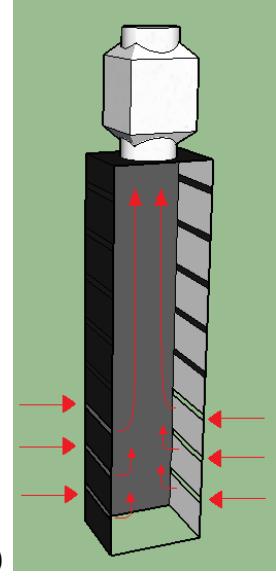

Figura 1 - Desenhos representando as geometrias: (a) equipamento completo; (b) leito fixo; (c) Configuração totalmente aberta (Caso 1); (d) Configuração parcialmente fechada (Caso 2).

O leito foi preenchido com folhas de Moringa Oleífera fresca até a altura aproximada de $0,57 \mathrm{~m}$, alcançando uma média de $1,4 \mathrm{~kg}$ de folhas por experimento. Ao longo do teste, foram feitas as coletas do material no interior do leito em todas as oito alturas das entradas de ar, a fim de se observar a secagem da moringa em cada bateria de ensaio.

\subsection{Procedimento de simulação}

O modelo de meios porosos, resumido na Tabela 1, usa o conceito de velocidade superficial do gás, que percola um meio poroso que apresenta uma resistência ao escoamento, determinada empiricamente em uma região definida como porosa (BÉTTEGA et al, 2013). Assim, resolvem-se as equações da continuidade (Eq. 1) e de conservação de momento (Eq. 2) apenas para o fluido e acrescenta-se um termo de dissipação à equação de quantidade de movimento (Eq. 3). A perda de carga relativa ao meio poroso é calculada pela Equação de Ergun (Eq. 4), sendo necessário informar como condição inicial as propriedades do meio poroso, ou seja, a permeabilidade (Eq. 5) e o coeficiente de perda inercial (Eq. 6), que é significativo quando o escoamento é turbulento (ANSYS FLUENT, 2016).

Tabela 1 - Sistema de equações para o escoamento multifásico gás-sólido

(1) Continuidade para a fase fluida escoando no meio poroso:

Equações:

$\frac{\partial}{\partial t}(\varepsilon \rho)+\nabla \cdot(\varepsilon \rho \vec{v})=0$

(2) Conservação de Momento para a fase fluida escoando no meio poroso:

$\frac{\partial}{\partial t}(\varepsilon \rho \vec{v})+\nabla \cdot(\varepsilon \rho \vec{v} \vec{v})=-\varepsilon \nabla p+\nabla \cdot(\varepsilon \vec{\tau})+\varepsilon \vec{B} f-\left(\frac{\varepsilon^{2} \mu}{K} \vec{v}+\frac{\varepsilon^{3} C_{2}}{2} \rho|\vec{v}| \vec{v}\right)$

(3) Termo fonte para o meio poroso homogêneo, $\mathrm{Si}$ :

$S_{i}=-\left(\frac{\mu}{\alpha} v_{j}+C_{2} \frac{1}{2} \rho|v| v_{j}\right)$

(4) Equação de Ergun para cálculo da perda de carga no meio poroso (regime turbulento):

$\frac{|\Delta p|}{L}=\frac{150 \mu}{D_{p}^{2}} \frac{(1-\varepsilon)^{2}}{\varepsilon^{3}} v+\frac{1,75 \rho}{D_{p}} \frac{(1-\varepsilon)}{\varepsilon^{3}} v^{2}$

(5) Relação constitutivas para cálculo da permeabilidade do meio poroso (ERGUN, 1952):

$\alpha=\frac{D_{p}^{2}}{150 \mu} \frac{\varepsilon^{3}}{(1-\varepsilon)^{2}}$

(6) Relações constitutivas para cálculo do coeficiente de perda inercial do meio poroso:

$C_{2}=\frac{3,5}{D_{p}} \frac{(1-\varepsilon)}{\varepsilon^{3}}$ 


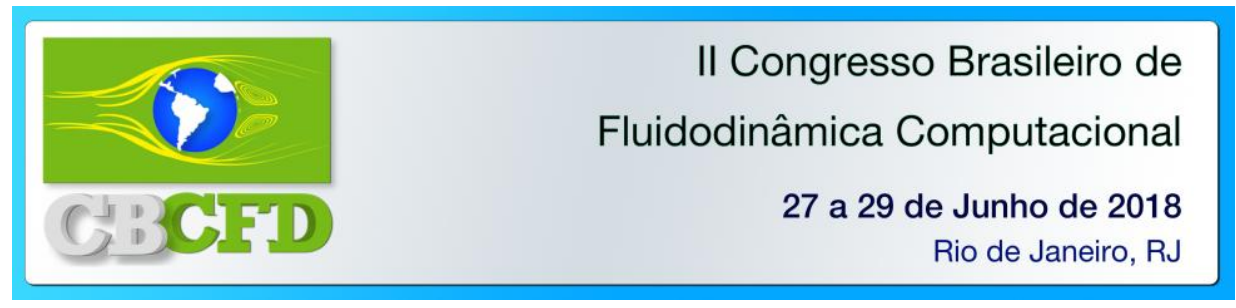

A análise realizada através da fluidodinâmica computacional (CFD) teve como foco avaliar o perfil de velocidade do ar escoando através do meio poroso que compõe o secador de leito fixo, na temperatura média do experimento de secagem, cerca de $45^{\circ} \mathrm{C}$. Foi criada uma malha computacional tridimensional com a mesma geometria do equipamento $(0,10 \times 0,14 \times 0,60 \mathrm{~m})$, contendo cerca de 249.852 elementos hexaédricos ao longo do leito e tetraédricos nas proximidades do exaustor. Para tal, empregou-se o software Gambit®.

O sistema de equações diferenciais parciais foi resolvido no software Fluent, empregado o método de volumes finitos, considerando que este fluido permeava um meio poroso com propriedades: permeabilidade de $1,24.10^{6} \mathrm{~m}^{-2}$ e resistência inercial de $5,70.10^{2} \mathrm{~m}^{-2}$. Como condições de contorno, foi definido uma velocidade de ar de $2 \mathrm{~m} / \mathrm{s}$ na saída do leito, onde se localiza o exaustor, e as aberturas laterais definiu-se como pressão atmosférica, na parede definiu-se velocidade do ar igual a zero (no-slip) e uma temperatura de operação de $318 \mathrm{~K}$, e altura de leito estático de $0,57 \mathrm{~m}$. Esquema de acoplamento pressão-velocidade foi dado pelo algoritmo SIMPLE O critério de convergência empregado foi de $1 \times 10^{-4}$. Empregou-se o modelo de turbulência $k-\varepsilon$ padrão. Durante as simulações, duas condições de alimentação de ar foram estudadas: todas as entradas laterais de ar abertas (Caso 1) e somente as três entradas na base do leito abertas (Caso 2), como mostrado na Fig. 1c e Fig. 1d, respectivamente.

\section{RESULTADOS E DISCUSSÃO}

Com relação aos contornos simulados de velocidade, nota-se que o Caso 2 (Fig. 2b) apresenta uma melhor distribuição do fluxo de ar que o Caso 1 (Fig 2a). Como no Caso 2 (parcialmente fechado) os caminhos preferenciais estão impedidos, o ar dentro do leito ganha maior velocidade desde as camadas mais inferiores, proporcionando uma secagem mais homogênea por todo o leito. Este fato também foi comprovado nas medições experimentais de fluxo de ar com uso de anemômetro (Fig. 3), em que os maiores valores de velocidade medidos foram observados para o Caso 2. Ao se comparar as Figuras 4 e 5, verificou-se que o aumento da intensidade de radiação solar, o ocorrido no período de 3 a 4 horas, ocasionou a elevação na temperatura do secador, enquanto que o aumento da velocidade do vento (ocorrido em 5 hs de secagem) contribuiu diminuindo a temperatura do equipamento.

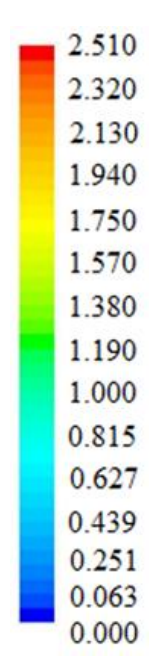

Figura 2 - Contornos de magnitude de velocidade do ar: (a) Caso 1 (totalmente aberto); (b) Caso 2 (semi-fechado).

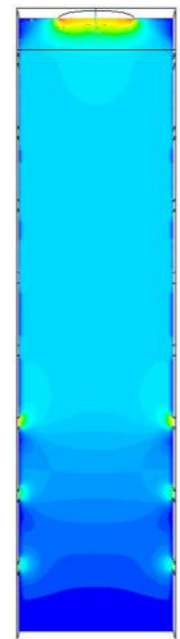

(b) Caso 2

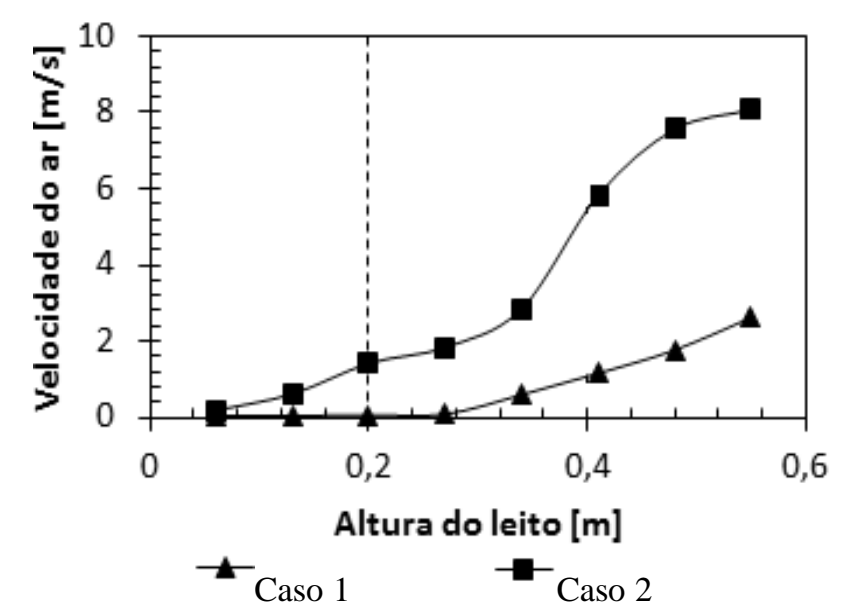

Figura 3 - Perfil axial experimental do fluxo de ar no leito: Caso 1 (totalmente aberto) e Caso 2 (parcialmente fechado). 

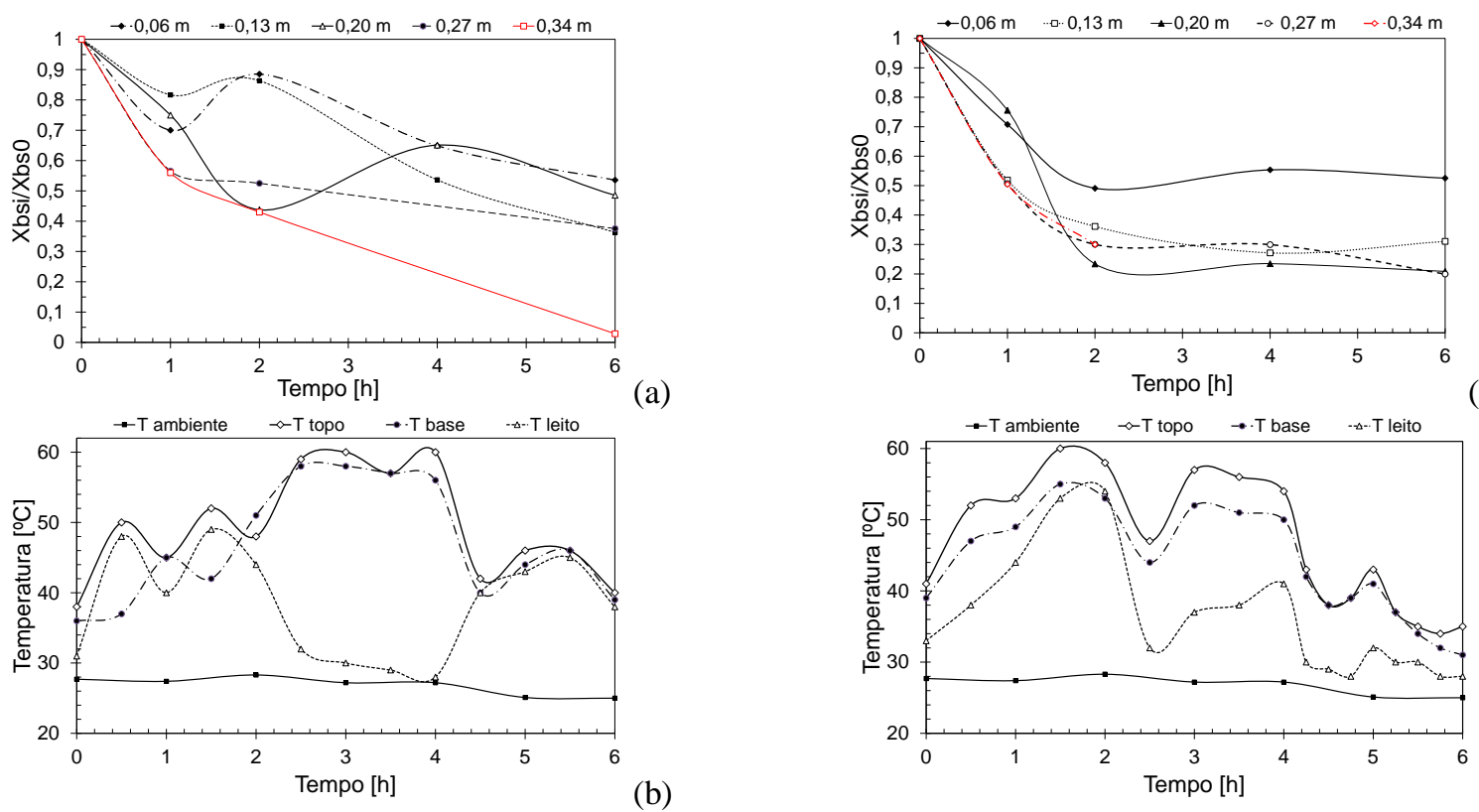

(a)
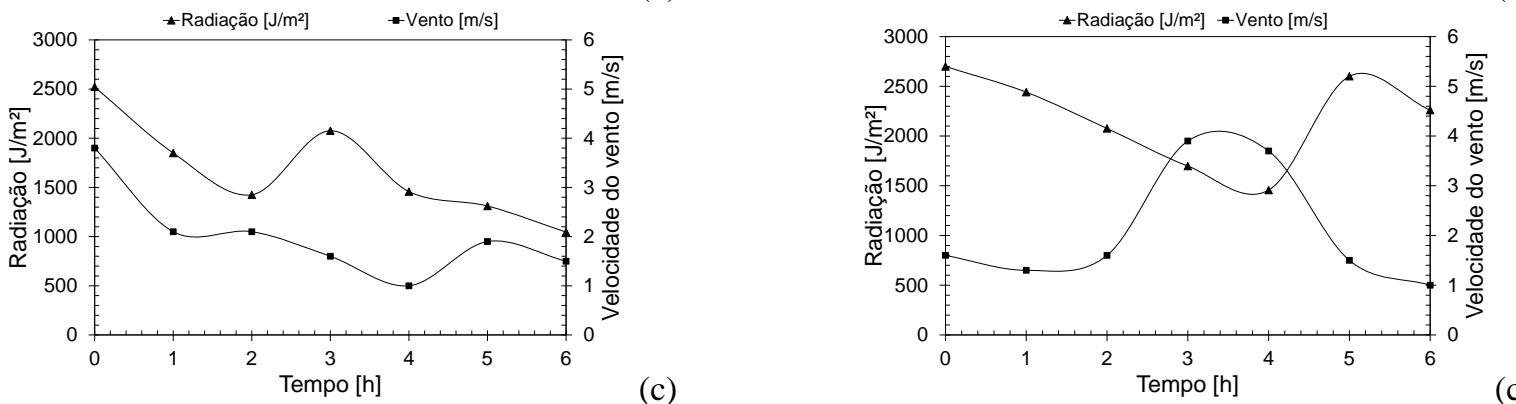

(b)

Figura 4 - Secagem solar (Caso 1): (a) Razão de secagem; (b) temperaturas; (c) Radiação e velocidade do vento.

Figura 5 - Secagem solar (Caso 2):

(a) Razão de secagem; (b) temperaturas; (c) Radiação e velocidade do vento.

\section{CONCLUSÃO}

As modificações propostas no presente estudo, quanto a alimentação lateral do ar para o interior do secador solar de leito fixo, permitiram verificar que ele se tornou mais eficiente e com secagem mais rápida na condição parcialmente fechada no topo, apenas com as entradas inferiores abertas, proporcionando assim uma secagem mais homogênea por todo o leito.

\section{REFERÊNCIAS}

ANSYS Fluent, 17.2, ANSYS, Canonsburg, 2016. http://www.ansys.com/products/fluids/ ansys-fluent.

BÉTTEGA; R. BARROZO, M. A. S. CORRÊA; R. G. FREIRE. J. T.. CFD Simulation of heat transfer inside packed beds: Evaluation of effective thermal conductivity. JP Journal oh Heat and Mass. Transfer, v. 8, n. 2, p.137-148, 2013.

ERGUN, S.. Fluid Flow through Packed Columns. Journal of Chem. Eng. Progress, v. 48, n.2, p. 89-94, 1952.

\section{AGRADECIMENTOS}

Os autores agradecem o suporte da Capes (AUXPE0856/2015) e Fapemig (PPM-00564-16). 